\title{
OPEN
}

Published online: 07 February 2020

\section{Author Correction: Rectosigmoidal manifestations of venous malformations: MR imaging findings and interdisciplinary therapeutic modalities}

\section{Richard Brill, Eva Brill, Wibke Uller D, Veronika Teusch, Hubert Gufler, Simone Hammer, Claudia Fellner, Katja Evert, Constantin Goldann, Maximilian Helm, Jonas Rosendahl \& Walter A. Wohlgemuth}

Correction to: Scientific Reports https://doi.org/10.1038/s41598-019-56217-0, published online 27 December 2019

The original version of this Article contained a typographical error in the spelling of the author Jonas Rosendahl, which was incorrectly given as Rosendahl Jonas. This has now been corrected in the PDF and HTML versions of the Article.

(c) The Author(s) 2020 